\title{
A RARE ASSOCIATION OF A BIG VESICAL CALCULUS WITH UTEROVAGINAL PROLAPSE: A CASE REPORT
}

Jayanta Ray ${ }^{1}$, Salil Bindu Chakraborty², Atanu Sarkar ${ }^{3}$

\section{HOW TO CITE THIS ARTICLE:}

Jayanta Ray, Salil Bindu Chakraborty, Atanu Sarkar. "A Rare Association of a Big Vesical Calculus with Uterovaginal Prolapse: A case report". Journal of Evolution of Medical and Dental Sciences 2014; Vol. 3, Issue 73, December 25; Page: 15445-15447, DOI: 10.14260/jemds/2014/4081

\begin{abstract}
Uterovaginal prolapse is a common gynaecological problem encountered in day today practice. Uterovaginal prolapse is usually associated with repeated childbirth trauma. Descent of urinary bladder, urethra, rectum, intestines are common. Associated urinary bladder prolapse leads to recurrent Urinary tract infection and obstructive uropathy. Infection and obstruction together leads to calculus formation in urinary bladder. A 38 years old multiparous lady with uterovaginal prolapse associated with vesical calculus treated by vaginal hysterectomy with suprapubic cystolithotomy. X ray KUB and Ultrasonography was diagnostic of vesical calculus. In this case report, there was associated giant urinary bladder calculus along with the Uterovaginal prolapse. This association is rare and needs meticulous surgery to treat all the associated problems simultaneously.
\end{abstract}

KEYWORDS: Uterovaginal prolapse, Big Vesical Calculus.

INTRODUCTION: Uterovaginal prolapse is a common gynaecological disorder seen in multiparous women. Prolapse is often associated with different urinary and bowel symptoms. Giant or big vesical calculus weighing $>100$ gm with uterine prolapse is very rare ${ }^{1,2}$. Urinary tract infection associated with prolonged out flow obstruction of urine is possible causative factors for vesical calculus formation in genital prolapse ${ }^{3}$. At times acute irreducible prolapse with urinary tract infection may be the presenting symptoms in a case of long standing inflammatory problem of vesical calculus with uterovaginal prolapse. Here we present one such case report of big vesical calculus associated with uterovaginal prolapse.

CASE REPORT: A 38 years old female unskilled laborer from rural Tripura presented to this tertiary care hospital with complaints of dribbling of urine and stool incontinence for 6 months, burning micturation off and on with variable urine out flow for last three years, along with uterine prolapse for last seven years since her last child birth. She is Para 4 with 2 living issues, all were home deliveries. Her last childbirth was a difficult home delivery and it was a still born girl. Her bladder control was poor with recent onset of severe dysuria for which she was referred from a rural health center to this tertiary care hospital. Earlier on different occasions, she was treated irregularly for urinary tract infections. Her menstrual cycle was regular. She was known hypertensive and had history of dysperunia. She was not diabetic or asthmatic.

On examination she was ill-nourished and her BMI was 19.4. She was pale and had tenderness over both flank region. Pelvic examination revealed third degree reducible uterovaginal prolapse with moderate rectocele and moderate cystocele. Bladder wall felt thick and a hard about $4 \mathrm{~cm}$ well circumscribed mobile mass felt through anterior fornix. On investigation, hemoglobin was $7.2 \mathrm{gm} \%$, serum urea $30 \mathrm{mg} / \mathrm{dl}$, creatinine $1.38 \mathrm{gm} / \mathrm{dl}$. There was $20-25$ pus cell/ HPF in urine and culture grown $\mathrm{E}$ coli which was sensitive to nitrofurantoin. $\mathrm{X}$ ray KUB detected large vesical calculus 


\section{CASE REPORT}

(Figure 1); Ultrasonography reveals bilateral grade 3 hydronephrosis with large vesicle calculus with uterovaginal prolapse. She was diagnosed as a case of Uterovaginal Prolapse with chronic Urinary Tract Infection with Vesical Calculus with pyelonephritis with Anemia. She received initial treatment for Pyelonephritis and Urinary Tract Infection and correction of anemia. Later she underwent vaginal hysterectomy with anterior colporrhaphy and colpoperiniorrhaphy along with suprapubic cystolithotomy. The procedure was uneventful. Immediate post-operative period bladder irrigation was maintained with three way catheter. The catheter drainage was maintained for 10 days. The calculus measured $5.3 \times 4.1 \times 3.2 \mathrm{~cm}$ and weighing $450 \mathrm{gm}$ (Figure 2 ). The post-operative period was uneventful. The patient was discharged on post-operative day 14 with excellent urinary control and renal parameters. At discharge her urine culture did not grow any organism and her $\mathrm{Hb}$ was 10.5 gm\%. And on follow up she is doing well.

DISCUSSION: Uterine prolapse occurs most commonly in multiparous and post-menopausal women because of injury to the endopelvic fascia and levator ani muscles. These injuries are more common in unskilled difficult home deliveries. Uterine prolapse may also be result of a pelvic tumor, estrogen deficiency, sacral nerve disorders, caudal anesthesia accidents or pre sacral tumor. Additional factor promoting uterine polapse include obesity, asthma, chronic bronchitis, ascites and large uterine and ovarian tumor. The incidence of urinary tract infection is $74 \%$ and hydronephrosis is $7-17 \%$ in patients with uterine prolapse. ${ }^{4}$ The association of uterovaginal prolapse and ureteral obstruction was initially reported in 1923 by Brettaver and Rubin. ${ }^{5}$ The incidence is 5\%; however, hydroureteronephrosis occur as often as $30-40 \%$ in patients with severe uterine prolapse. ${ }^{6}$

The association of uterine prolapse and ureteral obstruction was initially reported in 1923 by. The obstruction occurs as the uterus descends; the downward traction of the uterine arteries located over the lower ureters cause the bladder trigone and lower ureters to be dragged outside the pelvis. Prolapse of the uterus is an important cause of recurrent urinary tract infections. It predisposes to incontinence and often leads to pyelonephritis, anemia, renal failure and hypertension. Recurrent urinary tract infection is one of the most important causes of vesicle calculus formation ${ }^{7}$ as with our case. This patient has different interrelated complications of Genitourinary prolapse.

The association between prolapse and obstructive uropathy is common. Delay in treatment may increase morbidity and lead to renal failure. It is therefore important to rule out renal structural and functional pathology in a case of uterine prolapse which is potentially reversible but often overlooked and results in serious renal disease.

\section{REFERENCES:}

1. Singal R, Goyal S, Sekhon MS, Pandit S. A rare giant urinary bladder stone: a case report. Urotoday Int J 2010; 3(3).

2. Johnson CG. Giant calculus in the urinary bladder associated with complete uterine prolapse: report of a case. Obstet Gynecol 1958; 11 (5): 579-80.

3. Shashidhar B, Krishna Shetty. Utervaginal prolapse with Giant Vesical Calculus: a rare case report. Indian J of Clinical Practice; 2013; 23(12): 837-39.

4. Gemer 0, Bergman M, Segal S. Prevalence of hydronephrosis in patients with genital prolapse. Eur J Obstet Gynecol Reprod Biol. 1999; 86 (1): 11-13. 


\section{CASE REPORT}

5. Brettaver J, Rubin IC. Hydroureter and hydronephrosis: a frequent secondary finding in cases of prolapse of uterus and bladder. Am J Obstet Gynecol 1923; 6: 696.

6. Kontogeorgos L, Vassilopolos P, Tentes A. Bilateral severe hydroureteronephrosis due to uterine prolapse. Br J Urol 1985; 57: 360.

7. Cooper HD, Krainik AJ, Lubear SJ. The Washington mannual of medical therapeutics. $32^{\text {nd }}$ edi. St. Louis, Washington, USA: Lippincott Williams \& Wilkins.2009 p 338-339.

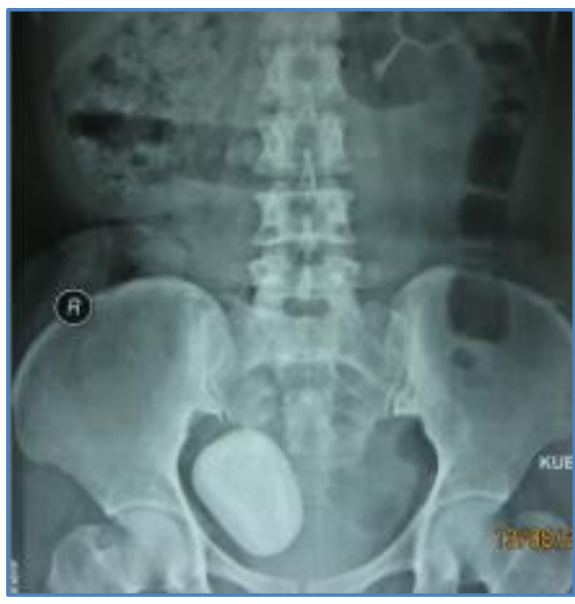

Fig. 1: Preoperative Plane X ray KUB

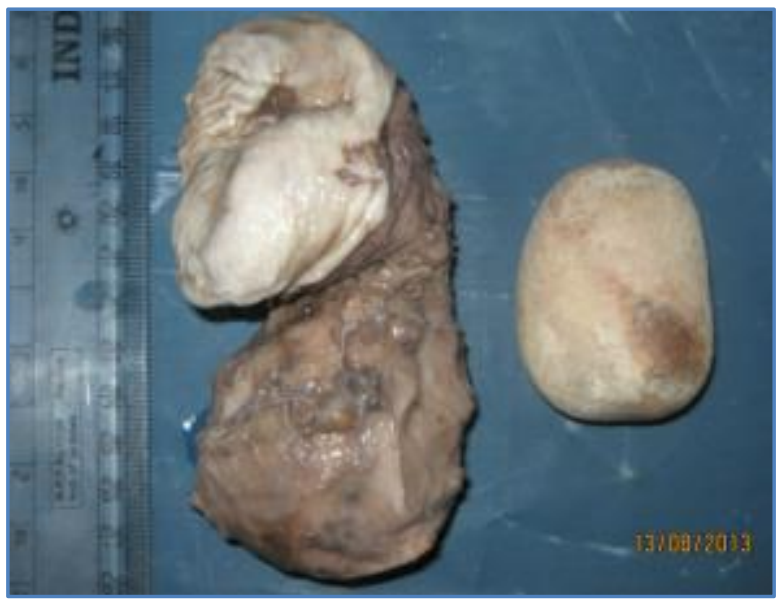

Fig. 2: Uterus and the Calculus after Surgery

\section{AUTHORS:}

1. Jayanta Ray

2. Salil Bindu Chakraborty

3. Atanu Sarkar

\section{PARTICULARS OF CONTRIBUTORS:}

1. Associate Professor, Department of Obstetrics and Gynaecology, Agartala Government Medical College.

2. Assistant Professor, Department of Obstetrics and Gynaecology, Agartala Government Medical College.

3. Junior Resident, Department of Obstetrics and Gynaecology, Agartala Government Medical College.

\section{NAME ADDRESS EMAIL ID OF THE CORRESPONDING AUTHOR: \\ Dr. Jayanta Ray, Palace Compound, Thakur Anil Krishna Sarani, Agartala, Tripura-799001. \\ Email: drjayantray@gmail.com}

Date of Submission: 06/12/2014. Date of Peer Review: 07/12/2014. Date of Acceptance: 17/12/2014. Date of Publishing: 24/12/2014. 